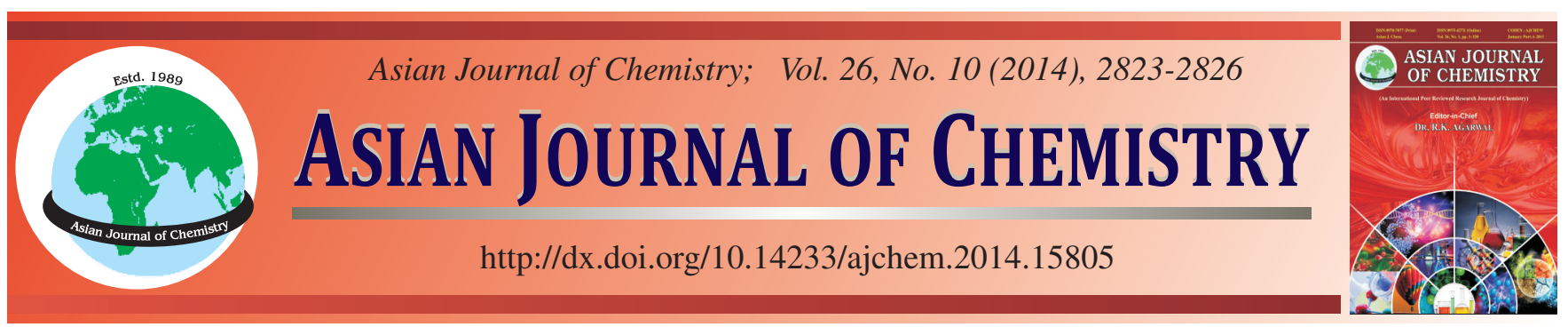

\title{
Purification of Two Flavones from Chamaecyparis obtusa by Solid-Phase Extraction
}

\author{
Y.R. LEE and K.H. Row*
}

Department of Chemical Engineering, Inha University, Incheon, Republic of Korea

*Corresponding author: Tel: +82 32 8607470; Fax: +82 32 8720959; E-mail: rowkho@inha.ac.kr

Received: 21 May 2013;

Accepted: 17 September 2013;

Published online: 10 May 2014;

AJC-15127

Solid phase extraction was used to purify two compounds obtained by Chamaecyparis obtusa. Commercial silica and amino silica, MCM-41 and amino MCM-41, respectively, which have a regular structure, were applied as sorbents to increase the purification efficiency. The adsorption isotherm confirmed amino MCM-41 to have higher absorption ability. Moreover, the two target compounds could be separated and purified by solid phase extraction using amino MCM-41 with different washing and elution solvents. Under optimal conditions, $4.93 \mu \mathrm{g} / \mathrm{g}$ of myricetin and $5.91 \mu \mathrm{g} / \mathrm{g}$ of amentoflavone were extracted from Chamaecyparis obtusa.

Keywords: Purification, Flavones, MCM-41, Solid phase extraction.

\section{INTRODUCTION}

Chamaecyparis obtusa (C. obtusa) is a species of cupressaceae native to central Japan that is distributed mainly in Korea, Japan, North America, Taiwan and north eastern China ${ }^{1,2}$. C. obtusa wood is generally used as a structural material, such as floor coverings ${ }^{3}$. The essential oils extracted from the leaves and twigs of $C$. obtusa are generally used as functional additives with a good fragrance in soaps, toothpaste and cosmetics ${ }^{4}$. C. obtusa essential oil has antibacterial, antifungal, antimite, antitermite and acaricidal activities ${ }^{5,6}$. Flavones are the other major active compounds in C. obtusa, including myricetin and amentoflavone (Fig. 1) and have antioxidant, anticancer and antiinflammatory activities ${ }^{7}$. Myricetin has a range of biological effects, such as spasmolytic, antiphlogistic, antiallergic, antiartherosclerotic and antihrombotic agents ${ }^{8}$. Amentoflavone has been evaluated for its analgesic and antiacetylcholinesterase activities $^{9,10}$.

Adsorption isotherms are normally uesd to determine the separation efficiency ${ }^{11}$. The complexity of adsorption and the errors in the experimental adsorption data have asignificant influence on the applications and development of adsorption technology $y^{12}$. The Langmuir-Freundlich model is the most popular equilibrium isotherm among the many non-linear isotherm models available ${ }^{13}$. The Langmuir-Freundlich isotherm equation has an additional three parameters compared to the other equations and a higher correlation accuracy has been reported ${ }^{14}$.

Solid-phase extraction (SPE) and is used widely for the preconcentration and clean-up of analytical samples, as well as<smiles>O=c1c(O)c(-c2cc(O)c(O)c(O)c2)oc2cc(O)cc(O)c12</smiles>

(1)<smiles>O=c1c(O)c(-c2ccc(O)c(-c3c(O)cc(O)c4c(=O)cc(O)oc34)c2)oc2cc(O)cc(O)c12</smiles>

(2)

Fig. 1. Structures of (1) myricetin and (2) amentoflavone

for the purification of range of chemicals and the removal of toxic or valuable substances. Solid-phase extraction avoids or minimizes the disadvantages of liquid-liquid extraction (LLE). Compared to liquid-liquid extraction, solid-phase extraction 
reduces the time required, particularly if automated methods are used. Solid-phase extraction can handle small samples (50$100 \mu \mathrm{L}$ ) and requires small solvent volumes. For analytical purposes, solid-phase extraction is generally performed using a small column or cartridge containing an appropriate packing ${ }^{15}$. The powdered plant is packed above the sorbent in a solidphase extraction cartridge. A fixed volume of extraction solvent is then percolated through the cartridge, which transfers the target compound to the sorbent. The solvent is then collected and used to repeat the process (extraction stage). After full extraction, the unnecessary compounds are removed from the sorbent and the purified target compound remaining are eluted (washing and elution stage) $)^{16}$.

This paper reports the use of different materials as solidphase extraction sorbents to extract and purify myricetin and amentoflavone from $C$. obtusa. The interactions between the target compounds and sorbent were compared using the adsorption isotherms.

\section{EXPERIMENTAL}

Myricetin and amentoflavone were obtained from SigmaAldrich (Milwaukee, WI, USA). Acetonitrile, methanol and acetic acid were purchased from Duksan Pure Chemical Co., Ltd. (Ansan, Korea). All other reagents used in the experiment were of the highest grade. Double distilled water was filtered using a vacuum pump (Division of Millipore, Waters, USA) and filter (HA-0.45, Division of Millipore, Waters, USA) prior to use. All samples were filtered through a filter (MFS-25, 0.2 $\mathrm{mm}$ TF, Whatman, USA) before being injected into the high performance liquid chromatography system.

Chromatographic condition: HPLC was performed with a Waters 600s multisolvent delivery system, Waters 616 liquid chromatography and waters 2487 variable wavelength, dualchannel UV detector (Waters Associates, Milford, MA, USA). A commercial C18 column $(4.6 \times 250 \mathrm{~mm}, 5 \mu \mathrm{m})$ purchased from RStech Co. (Daejeon, Korea) was used.

The flavones were separated by HPLC using acetonitrile/ water/acetic acid (40:60:0.5, v/v/v) as the mobile phase. The flow rate, UV wavelength and injection volume were set to $0.5 \mathrm{~mL} / \mathrm{min}, 372 \mathrm{~nm}$ and $10 \mu \mathrm{L}$, respectively.

Preparation of standard solutions and sample solution: Stock solutions of the two target compounds $(100 \mu \mathrm{g} / \mathrm{mL})$ was prepared in $1 \mathrm{~mL}$ methanol. C. obusa leaves were powdered and $10 \mathrm{~g}$ of the resulting powder was weighed and extracted with $100 \mathrm{~mL}$ of methanol by heating under reflux at $60{ }^{\circ} \mathrm{C}$ for $2 \mathrm{~h}$. After centrifugation and filtration, the extract was collected and stored for later use.

Solid-phase extraction procedure: Commercial solidphase extraction cartridges (diameter $0.9 \mathrm{~cm}, 3.0 \mathrm{~mL}$ ) with $0.2 \mathrm{~g} \mathrm{C} 18$, silica and $\mathrm{NH}_{2}$-silica sorbent were purchased from Alltech (Deerfield, IL, USA) and MCM-41 (3.0 nm pore diameter, surface area $=800 \mathrm{~m}^{2} / \mathrm{g}$ ) was supplied by Hailong Tech Development Co. Ltd (Binzhou, China). $2.0 \mathrm{~g}$ of MCM41 and $\mathrm{NH}_{2}-\mathrm{MCM}-41$ were packed separately at the bottom of the empty polypropylene cartridge and preconditioned with methanol. The sample solution $(0.2 \mathrm{~mL})$ was loaded into the solid-phase extraction cartridge, washed sequentially with methanol, water and $n$-hexane and eluted with methanol, acetonitrile and acetonitrile-acetic acid (95:5, v/v).
Preparation of absorption isotherm: The static method was performed on the $\mathrm{NH}_{2}-\mathrm{MCM}-41$ particles. $2.0 \mathrm{mg} \mathrm{\textrm {NH } _ { 2 } -}$ MCM-41 was placed into microtubes and mixed with $1.0 \mathrm{~mL}$ of the standard flavone solutions $(0.5,1.0,2.0,4.0,5.0 \mu \mathrm{g} /$ $\mathrm{mL}$ ) at room temperature for $72 \mathrm{~h}$ until it reached equilibrium. The adsorption solution was centrifuged and the supernatant solvent was collected and filtered $(0.2 \mu \mathrm{m})$. The experimental adsorption isotherms were fitted to three models: linear, Freundlich and Langmuir-Freundlich models. This process was accomplished using the solver function in OriginPro 7.5 software (Origin Lab Corporation, MA, USA) by varying the fitting parameters until the squared correlation coefficient $\left(\mathrm{r}^{2}\right)$ reached 1 unity.

\section{RESULTS AND DISCUSSION}

A series of mixtures of standard solutions containing myricetin and amentoflavone were diluted $(0.5,1,2,4$ and 5 $\mu \mathrm{g} / \mathrm{mL}$ ) with methanol. The resulting linear regression equations of the two compounds were $\mathrm{Y}=596371 \times-172977\left(\mathrm{r}^{2}=\right.$ $0.9994)$ for myricetin and $Y=233484 \times-47316\left(r^{2}=0.9999\right)$ for amentoflavone. Where, $\mathrm{Y}$ and $\mathrm{X}$ represent the peak area of the analytes and concentration of the analytes in the C. obtusa leaves, respectively. Assays of the repeatability calculated as the relative standard deviations (RSDs) were performed by injecting standard solutions 5 times in a 5-day period. RSDs lower than $8.55 \%$ showed acceptable precision and accuracy.

The amount $(\mathrm{Q})$ of myricetin and amentoflavone adsorbed on $\mathrm{NH}_{2}$-MCM-41 was determined using the following equation:

$$
\mathrm{Q}=\frac{\left(\mathrm{C}_{0}-\mathrm{C}\right) \mathrm{V}}{\mathrm{m}}
$$

where Q $(\mu \mathrm{g} / \mathrm{g})$ is the amount absorbed, $\mathrm{C}_{0}(\mu \mathrm{g} / \mathrm{mL})$ is the initiator concentration, $\mathrm{C}(\mu \mathrm{g} / \mathrm{mL})$ is the free concentration, $\mathrm{V}$ $(\mathrm{mL})$ is the volume of the sample solvent and $\mathrm{m}(\mathrm{g})$ is the dry mass of the sorbent. Q was calculated using equation (1), The experimental parameters were compared by non-linear regression analysis using the equilibrium isotherms.

Purification of myricetin and amentoflaveone by solidphase extraction: Commercial $\mathrm{C}_{18}$, silica, $\mathrm{NH}_{2}$-silica, $\mathrm{MCM}$ 41 sorbent prepared. The $\mathrm{NH}_{2}-\mathrm{MCM}-41$ sorbent is synthesis for compared of amount of adsorption with commercial sorbent. MCM-41 is a popular material known as a mesoporous material. On the other hand, the surface of unmodified MCM-41 contains only hydroxyl groups $(-\mathrm{OH})$. Therefore the adsorption and selectivity of the target compounds on MCM-41 cannot be controlled. The separation efficiency can be increased by surface modification of the sorbent ${ }^{17,18}$. Fig. 2 shows structure of MCM-41 and $\mathrm{NH}_{2}-\mathrm{MCM}-41$.

Selecting the washing solvent and elution solvent is an important process in solid-phase extraction. The removal of interfering compounds in the washing stage is important for obtaining the target compounds in the elution stage. Table-1 lists the amounts of target compounds in the different washing solvents. Large or weakly interacting molecules can be removed due to the sorbent structure and pore size of the sorbents. Hydrophobic and hydrophilic interference could be washed out without the target compound using $n$-hexane and water, respectively. Only water could remove the interference compounds 

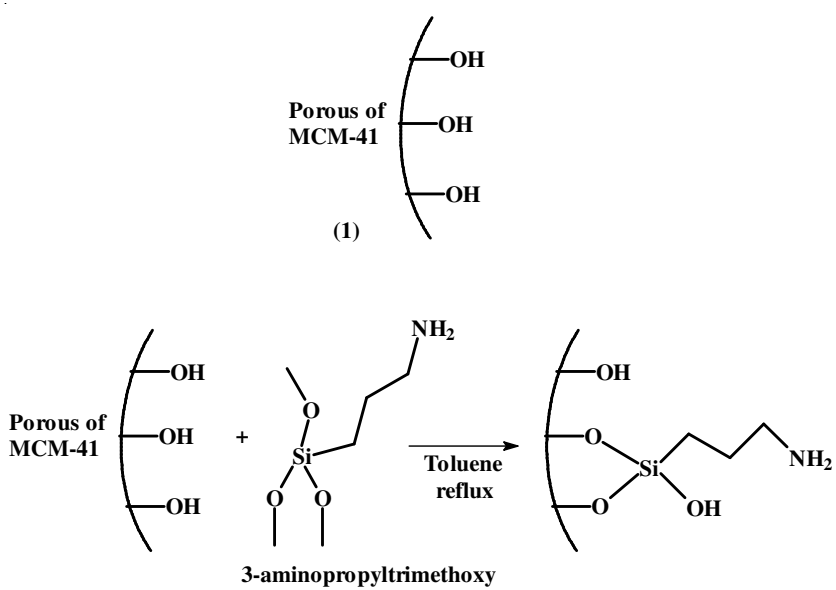

(2)

Fig. 2. Structure of (1) MCM-41 and (2) $\mathrm{NH}_{2}-\mathrm{MCM}-41$

TABLE-1

AMOUNTS OF THE TWO TARGET COMPOUNDS REMAINING IN THE DIFFERENT WASHING SOLVENTS AND SORBENTS

\begin{tabular}{|c|c|c|c|}
\hline $\begin{array}{l}\text { Washing } \\
\text { solvent }\end{array}$ & Sorbent & \multicolumn{2}{|c|}{$\begin{array}{c}\text { Amount }(\mu \mathrm{g} / \mathrm{g}) \\
\text { Myriectin Amentoflavone }\end{array}$} \\
\hline \multirow{5}{*}{ Methanol } & $\mathrm{C}_{18}$ & 2.900 & 10.475 \\
\hline & Silica & 2.927 & 13.302 \\
\hline & $\mathrm{NH}_{2}$-silica & 2.946 & 2.199 \\
\hline & MCM-41 & 2.972 & 6.427 \\
\hline & $\mathrm{HN}_{2}-\mathrm{MCM}-41$ & 5.067 & 6.782 \\
\hline \multirow{5}{*}{ Water } & $\mathrm{C}_{18}$ & ND & ND \\
\hline & Silica & ND & ND \\
\hline & $\mathrm{NH}_{2}$-silica & ND & ND \\
\hline & MCM-41 & ND & ND \\
\hline & $\mathrm{HN}_{2}-\mathrm{MCM}-41$ & ND & ND \\
\hline \multirow{5}{*}{$n$-hexane } & $\mathrm{C}_{18}$ & 3.006 & 2.572 \\
\hline & Silica & 3.063 & 3.904 \\
\hline & $\mathrm{NH}_{2}$-silica & 2.989 & 11.290 \\
\hline & MCM-41 & 3.030 & 6.648 \\
\hline & $\mathrm{HN}_{2}-\mathrm{MCM}-41$ & ND & ND \\
\hline
\end{tabular}

with the lowest concentration of target compounds. The target compounds were soluble in organic solvents, such as ethanol and ether, but insoluble in water. Therefore, water was selected as the washing solvent and fixed at $2 \mathrm{~mL}$. Table- 2 lists the amounts of target compounds remaining in the different elution solvents. After the washing stage, the highest amounts of target compounds were extracted in the elution stage using $2 \mathrm{~mL}$ methanol as the elution solvent. The optimal solid-phase extraction conditions were as follows: water as the washing solvent and methanol as the elution solvent. Under this condition, the quantities of myricetin and amentoflavone obtained were $4.93 \mu \mathrm{g} / \mathrm{g}$ and $5.91 \mu \mathrm{g} / \mathrm{g}$, respectively. Fig. 3 shows the solid-phase extraction process for purifying the target compounds.

Analysis of the adsorption isotherms: Fig. 4 shows the amount of myricetin and amentoflavone absorbed on $\mathrm{NH}_{2}-$ MCM-41. More myricetin then amentoflavone was adsorbed on the same surface area of the solid phase. This was attributed to the smaller molecular size of myricetin than amentoflavone ${ }^{19}$
TABLE-2

AMOUNTS OF THE TWO TARGET COMPOUNDS REMAINING IN THE DIFFERENT ELUTION SOLVENT S AND SORBENTS

\begin{tabular}{|c|c|c|c|}
\hline Elution solvent & Sorbent & \multicolumn{2}{|c|}{$\begin{array}{c}\text { Amount }(\mu \mathrm{g} / \mathrm{g}) \\
\text { Myriectin amentoflavone }\end{array}$} \\
\hline \multirow{5}{*}{ Methanol } & $\mathrm{C}_{18}$ & 2.913 & 3.347 \\
\hline & Silica & 2.909 & 3.279 \\
\hline & $\mathrm{NH}_{2}$-silica & 3.060 & 4.644 \\
\hline & MCM-41 & 2.910 & 3.160 \\
\hline & $\mathrm{HN}_{2}-\mathrm{MCM}-41$ & 4.933 & 5.911 \\
\hline \multirow{5}{*}{ Acetonitrile } & $\mathrm{C}_{18}$ & 2.925 & 2.947 \\
\hline & Silica & 2.917 & 2.237 \\
\hline & $\mathrm{NH}_{2}$-silica & 2.953 & 4.344 \\
\hline & MCM-41 & 2.922 & 2.506 \\
\hline & $\mathrm{HN}_{2}-\mathrm{MCM}-41$ & 2.960 & 3.469 \\
\hline \multirow{5}{*}{$\begin{array}{l}\text { Acetonitrile: } \\
\text { acetic acid } \\
(98: 2 \mathrm{v} / \mathrm{v})\end{array}$} & $\mathrm{C}_{18}$ & ND & 0.495 \\
\hline & Silica & ND & ND \\
\hline & $\mathrm{NH}_{2}$-silica & ND & 1.838 \\
\hline & MCM-41 & ND & 0.742 \\
\hline & $\mathrm{HN}_{2}-\mathrm{MCM}-41$ & ND & 1.945 \\
\hline
\end{tabular}

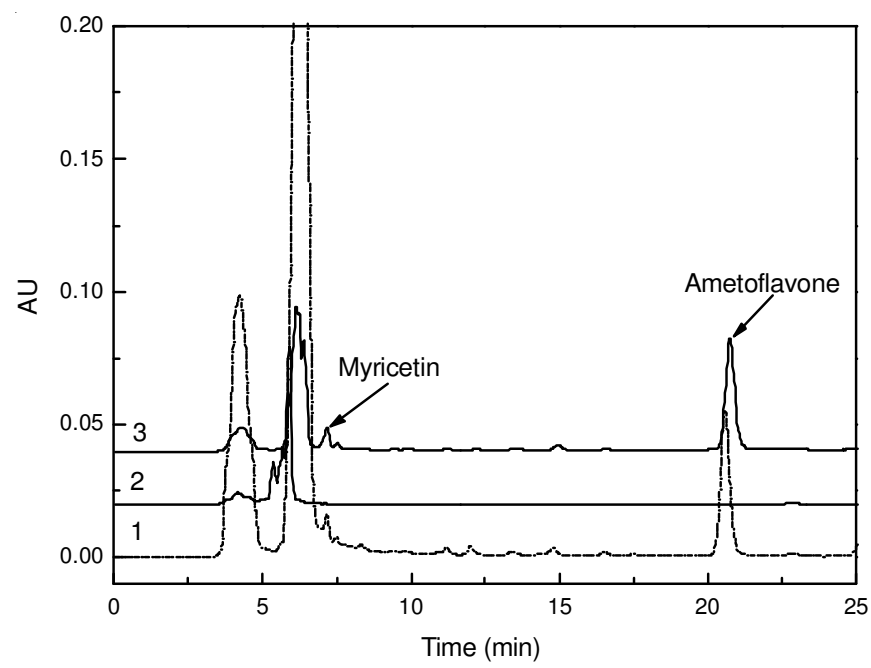

Fig. 3. Chromatograms of the water washing solvent and methanol elution solvent in $\mathrm{NH}_{2}-\mathrm{MCM}-41$ (Mobile phase: acetonitrile-water-acetic acid $=40: 60: 0.5(\mathrm{v} / \mathrm{v} / \mathrm{v})$, flow rate: $0.5 \mathrm{~mL} / \mathrm{min}$, column: C18 (4.6 $\times 250 \mathrm{~mm}, 5 \mu \mathrm{m}), \mathrm{UV}: 372 \mathrm{~nm}$, injection volume: $10 \mu \mathrm{L}, 1: C$. obtusa extraction sample, 2: water washing stage, 3: methanol elution stage)

The experiment data of myricetin and amentoflavone was fitted to the following three adsorption isotherm models:

$$
\begin{gathered}
\mathrm{Q}=\frac{\mathrm{aC}_{\mathrm{E}}}{1+\mathrm{BC}_{\mathrm{E}}} \\
\mathrm{Q}=\mathrm{aC}_{\mathrm{E}}^{\mathrm{b}} \\
\mathrm{Q}=\frac{\mathrm{abC_{E } ^ { \mathrm { c } }}}{1+\mathrm{bC}_{\mathrm{E}}^{\mathrm{c}}}
\end{gathered}
$$

where $a, b$ and $c$ are parameters and $C_{E}(\mu \mathrm{g} / \mathrm{mL})$ is the concentration of myricetin and amentoflavone in the standard solution samples. The adsorption isotherm models used were the Langmuir (eqn. 2), Freundlich (eqn. 3) and Langmuir- Freundlich (eqn. 4). Table-3 lists the adsorption parameters using the three adsorption isotherm models. The Langmuir-Freundlich isotherm 


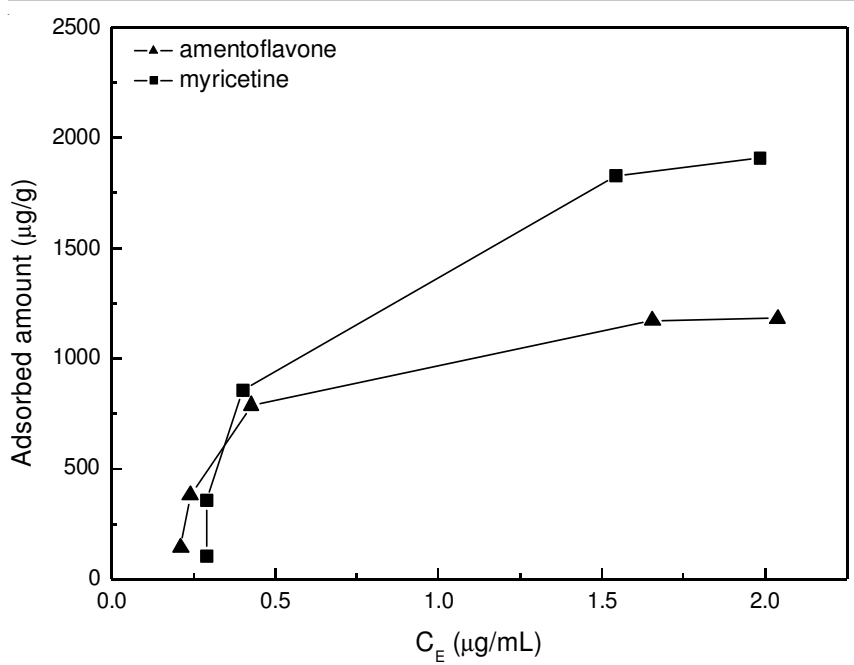

Fig. 4. Quantities of the target compounds absorbed on $\mathrm{NH}_{2}-\mathrm{MCM}-41$

was used to better compare the competitive adsorption. The regression coefficient $\left(\mathrm{r}^{2}\right)$ of the competitive LangmuirFreundlich of myricetin and amentoflavone was 0.9888 and 0.9858 , respectively.

TABLE-3

PARAMETERS FOR THE ADSORPTION ISOTHERM OF THE TWO TARGET COMPOUNDS BY NH $\mathrm{N}_{2}-\mathrm{MCM}-41$

\begin{tabular}{|c|c|c|c|c|c|}
\hline $\begin{array}{l}\text { Target } \\
\text { compounds }\end{array}$ & Parameters & $\mathrm{a}$ & b & $\mathrm{c}$ & $\begin{array}{l}\text { Regression } \\
\text { coefficient }\end{array}$ \\
\hline \multirow[t]{3}{*}{ Myricetin } & Langmuir & 2157.44 & 1.27 & - & 0.9018 \\
\hline & Freundlich & 1239.61 & - & 0.91 & 0.9472 \\
\hline & $\begin{array}{l}\text { Langmuir- } \\
\text { Freundlich }\end{array}$ & 1137.67 & 0.13 & 2.39 & 0.9888 \\
\hline \multirow[t]{3}{*}{ Amentoflavone } & Langmuir & 2157.55 & 1.27 & - & 0.9018 \\
\hline & Freundlich & 928.03 & 0.64 & - & 0.9074 \\
\hline & $\begin{array}{l}\text { Langmuir- } \\
\text { Freundlich }\end{array}$ & 1181.44 & 30.07 & 3.133 & 0.9858 \\
\hline
\end{tabular}

\section{Conclusion}

This study compared the ability of $\mathrm{C} 18$, silica, aminosilica, MCM-41 and amino-MCM-41 to separate the two flavones from C. obtusa. Amino MCM-41 showed better separation and purification of the target compounds in the solid-phase extraction process. Under the optimized conditions of $2 \mathrm{~mL}$ of water as the washing solvent and $2 \mathrm{~mL}$ of methanol as the elution solvent, $4.93 \mu \mathrm{g} / \mathrm{g}$ of myricetin and $5.911 \mu \mathrm{g} / \mathrm{g}$ of amentoflavone were obtained.

\section{ACKNOWLEDGEMENTS}

This study was supported by the Basic Science Research Program through the National Research Foundation (NRF) of Korea funded by the Ministry of Education, Science and Technology (2012-0005250).

\section{REFERENCES}

1. S. Koyama, Y. Yamaguchi, S. Tanaka and J. Motoyoshiya, Gen. Pharmacol., 28, 797 (1997).

2. Y.M. Zhang, J. Xu, L. Xiao, G.Z. Zeng, Z.H. Sun and N.H. Tan, Molecules, 18, 1255 (2013).

3. M. Satoru, Y. Shuichiro and Y. Tsuyoshi, J. For. Res., 3, 27 (2003).

4. M.J. Park, W.S. Choi, H.Y. Kang, K.S. Gwak, G.S. Lee, E.B. Jeung and I.G. Choi, J. Microbiol., 48, 496 (2010).

5. E.-J. Hong, K.-J. Na, I.-G. Choi, K.-C. Choi and E.-B. Jeung, Biol. Pharm. Bull., 27, 863 (2004).

6. Y. Ohtani, M. Hazama and K. Sameshima, Mokuzai Gakkaishi, 49, 1022 (1997).

7. M. Tian, D. Han and K.H. Row, Anal. Lett., 44, 737 (2011).

8. K.C. Ong and H.E. Khoo, Gen. Pharmacol., 29, 121 (1997).

9. H.K. Kim, K.H. Son, H.W. Chang, S.S. Kang and H.P. Kim, Arch. Pharm. Res., 21, 406 (1998).

10. I. Erdogan-Orhan, M.L. Altun, B. Sever-Yilmaz and G. Saltan, J. Med. Food, 14, 434 (2011).

11. Y. Jin and K.H. Row, Korean J. Chem. Eng., 22, 264 (2005).

12. A.R. Khan, M.R. Riazi and Y.A. Al-Roomi, Sep. Purif. Technol., 18, 237 (2000).

13. M. Juza, J. Chromatogr. A, 865, 35 (1999).

14. Y. Bayrak, Micropor. Mesopor. Mater., 87, 203 (2006).

15. C.W. Huck and G.K. Bonn, J. Chromatogr. A, 885, 51 (2000).

16. M. Tian, W. Bi and K.H. Row, J. Chem. Technol. Biotechnol., 87, 165 (2012).

17. M.R. Mello, D. Phanon, G.Q. Silveira, P.L. Llewellyn and C.M. Ronconi, Micropor. Mesopor. Mater., 143, 174 (2011).

18. A.M.B. Furtado, Y. Wang, T.G. Glover and M.D. LeVan, Micropor. Mesopor. Mater., 142, 730 (2011).

19. A.W. Marczewski, A. Derylo-Marczewska and M. Jaroniec, J. Colloid Interf. Sci., 109, 310 (1986). 